This item was submitted to Loughborough's Research Repository by the author.

Items in Figshare are protected by copyright, with all rights reserved, unless otherwise indicated.

\title{
Dextran preserves native corneal structure during decellularization
}

PLEASE CITE THE PUBLISHED VERSION

http://dx.doi.org/10.1089/ten.tec.2016.0017

\section{PUBLISHER}

(C) Mary Ann Liebert, Inc.

\section{VERSION}

AM (Accepted Manuscript)

\section{PUBLISHER STATEMENT}

This work is made available according to the conditions of the Creative Commons Attribution-NonCommercialNoDerivatives 4.0 International (CC BY-NC-ND 4.0) licence. Full details of this licence are available at: https://creativecommons.org/licenses/by-nc-nd/4.0/

\section{LICENCE}

CC BY-NC-ND 4.0

\section{REPOSITORY RECORD}

Lynch, Amy P., Sammy Wilson, and Mark Ahearne. 2019. "Dextran Preserves Native Corneal Structure During Decellularization". figshare. https://hdl.handle.net/2134/23206. 


\title{
Dextran preserves native corneal structure during decellularization
}

\author{
Amy P. Lynch ${ }^{1,2}$, Samantha L. Wilson ${ }^{3,4^{*}}$ and Mark Ahearne ${ }^{1,2^{*}}$
}

\begin{abstract}
${ }^{1}$ Trinity Centre for Bioengineering, Trinity Biomedical Sciences Institute, Trinity College
Dublin, Pearse Street, Dublin 2, Republic of Ireland, ${ }^{2}$ Department of Mechanical and Manufacturing Engineering, School of Engineering, Trinity College Dublin, Ireland, ${ }^{3}$ Academic Ophthalmology, Division of Clinical Neuroscience, University of Nottingham, Queens Medical Centre campus, Nottingham, NG7 2UH, United Kingdom, ${ }^{4}$ Centre for Biological Engineering, Wolfson School of Mechanical, Manufacturing and Electrical Engineering, Loughborough University, Loughborough, LE11 2TU, United Kingdom
\end{abstract}

* Corresponding authors:

Mark Ahearne; Trinity Centre for Bioengineering, Trinity Biomedical Sciences Institute, Trinity College Dublin, Pearse Street, Dublin 2, Republic of Ireland. Tel.: +353 1 8964204; fax: +353 1 6795554; E-mail address: ahearnm@tcd.ie

Samantha L Wilson; Academic Ophthalmology, Division of Clinical Neuroscience, University of Nottingham, Queens Medical Centre campus, Nottingham, NG7 2UH, United Kingdom; Tel.: +44 (0) 1559 249924; E-mail address: Samantha.wilson@nottingham.ac.uk; S.Wilson2@lboro.ac.uk

Grant Information: Research supported by Science Foundation Ireland and Marie-Curie Action COFUND (11/SIRG/B2104); EPSRC Engineering, Tissue Engineering and Regenerative Medicine (EP/I017801/1) and COST Action BM-1302 short-term scientific mission. 


\begin{abstract}
Corneal decellularization has become an increasingly popular technique for generating scaffolds for corneal regeneration. Most decellularization procedures result in tissue swelling, thus limiting their application. Here the use of a polysaccharide, dextran, to reduce swelling and conserve the native corneal structure during decellularization was investigated. Corneas were treated with $1 \%$ Triton $\mathrm{X}-100,0.5 \%$ SDS and nucleases under constant rotation followed by extensive washing. To reduce swelling, decellularization solutions were supplemented with 5\% dextran either throughout the whole decellularization process or during the washing cycles only. Quantitative analysis of DNA content showed a $96 \%$ reduction after decellularization regardless of the addition of dextran. Dextran resulted in a significant reduction in swelling from $3.85 \pm 0.43 \mathrm{~nm}$ without to $1.94 \pm 0.29-2.01 \pm 0.37 \mathrm{~nm}$ $(p<0.05)$ remaining at similar dimensions to the native tissue $(1.73 \pm 0.23 \mathrm{~nm})$. Tissue transparency was restored to all decellularized corneas following submersion in glycerol. TEM analysis found that dextran must be present throughout the decellularization protocol to preserve the native corneal architecture, anisotropy analysis demonstrated comparable results $(0.22 \pm 0.03)$ to the native cornea $(0.24 \pm 0.02), p>0.05$. Dextran can counteract the detrimental effects of decellularizing agents on the biomechanical properties of the tissue resulting in similar compressive moduli (mean before decellularization: $5.40 \pm 1.18 \mathrm{kPa}$; mean after decellularization with dextran: $5.64 \pm 1.34 \mathrm{kPa}, p>0.05)$. Cells remained viable in the presence of decellularized scaffolds. The findings of this study indicate that dextran not only prevents significant corneal swelling during decellularization but also enhances the maintenance of the native corneal ultrastructure.
\end{abstract}

Keywords: Cornea, decellularization, swelling, extracellular matrix, ultrastructure, transparency, residual DNA, collagen, glycosaminoglycans 


\section{Introduction}

Corneal blindness affects millions worldwide and represents a significant global health challenge $(1,2)$. In many cases, the only therapeutic option is keratoplasty (3). This approach, suffers a number of limitations including a shortage of suitable donor tissue in many countries. In recent years, corneal tissue engineering has emerged as a promising alternative to transplantation and significant progress has been made in this area with keratoprostheses $(4,5)$, xenografts $(6-8)$ and tissue-engineered corneas (9) entering clinical or pre-clinical development.

Tissue-engineering approaches rely on the fabrication of biomimetic corneal scaffolds using synthetic and naturally-derived polymeric biomaterials (10-17). These scaffolds often fail to replicate the complex native structural and biochemical architecture of cornea (18). Decellularized corneas overcome many of the limitations of other tissue-engineered methods since the inherent structural features are already present in the scaffold, they possess the required nanoscale topography and intrinsic biological cues reside within the matrix that support healthy cell phenotypes (19). Decellularization involves removing nuclear and cellular material whilst preserving the structural components of the extracellular matrix (ECM) (20). Scaffolds derived by this method from a variety of tissues and organs have had clinical success $(21,22)$, however, worldwide shortage of viable cadaveric corneal tissue has led to the exploration of alternative tissue sources.

Xenogenic porcine corneal scaffolds have attracted considerable interest in recent years (2325), since they are inexpensive, readily available, and possess similar dimensional and refractive properties compared to human corneas (8). Decellularization of porcine tissue has been achieved through multiple methods; however, as yet, a universal set of standardized protocols has not been outlined. A significant problem arising from decellularization 
processes is corneal swelling, limiting its potential use as a scaffold. Tissue swelling results in a scaffold with dimensions incompatible with the human eye and thus is unsuitable for transplantation. In addition, the highly organized ECM architecture that is essential to corneal transparency $(26,27)$ becomes disrupted after swelling and decellularization treatments leading to a reduction in the optical clarity of the cornea. Furthermore, ECM damage can alter the mechanical properties of the cornea (28). The mechanical properties of the native corneas must be approximated in any successful corneal replacement, and is required to withstand internal and external forces that are applied to the eye, e.g. intraocular and eyelid pressure and eye rubbing (29-31). Dextran is a complex polysaccharide routinely used at a concentration of 5\% to act as a deswelling agent during organ culture to preserve human corneas (32-35) although to date its use in controlling swelling during decellularization has not been investigated. Dextran increases colloidal osmotic pressure in cornea storage medium, limiting movement of water into the stroma by maintaining a high osmotic pressure (34). In this study, we systematically evaluated the effect of dextran on swelling and ultrastructural maintenance of the cornea during decellularization.

\section{Methods}

All chemicals and reagents were purchased from Sigma-Aldrich, unless otherwise stated.

\section{Dissection of porcine corneas}

Adult porcine eyes were obtained from a local abattoir within $2 \mathrm{~h}$ post mortem. $8 \mathrm{~mm}$ corneal buttons were dissected and washed for $18 \mathrm{~h}$ in phosphate buffered saline (PBS) containing $2 \%(v / v)$ antibiotic/antimycotic $(0.02 \mu \mathrm{g} / \mathrm{mL}$ gentamycin, $0.5 \mathrm{ng} / \mathrm{mL}$ amphotericin B combination, Gibco; hereafter referred to as antibiotic/antimycotic wash solution). 


\section{Generation of an acellular porcine scaffold}

Four corneal groups were tested: (i) agitated control, $2 \%$ antibiotic/antimycotic wash solution; (ii) detergent treatment, $0.5 \%(w / v)$ sodium dodecyl sulphate (SDS) and $1 \%(v / v)$ Triton $\mathrm{X}-100$ in $\mathrm{diH}_{2} \mathrm{O}$; (iii) detergent/dextran treatment, as detergent treatment with the addition of $5 \%(w / v)$ dextran throughout the procedure; (iv) detergent/dextran wash treatment, as detergent treatment followed by washing in 5\% dextran. An additional control group, native cornea, represented freshly dissected corneas that did not undergo processing, except for brief washing in $2 \%$ antibiotic/antimycotic wash solution before analysis. All conditions were mechanically agitated on a gyratory rocker at $70 \mathrm{rpm}$ for $72 \mathrm{~h}$ at room temperature (RT). Corneas, except agitated control, were then treated with nucleases as previously described (12). All corneas were then washed for $48 \mathrm{~h}$ with PBS containing $1 \%$ antibiotic/antimycotic. This was supplemented with 5\% dextran for the detergent/dextran and detergent/dextran wash groups.

\section{Scaffold swelling}

Following decellularization, corneal swelling was analysed. Images were recorded using a stereo microscope (Leica S6 D, Leica Microsystems) coupled to a digital camera (Canon PowerShot S50 5MP, Canon). Corneal thickness was measured at the centre of the tissue with a micrometre calliper (Silverline) using 12 individual samples for each condition.

\section{Corneal transparency and light transmittance}

To evaluate changes in transparency porcine corneas were imaged following decellularization. Subsequently the corneas were submerged in $100 \%$ glycerol for $18 \mathrm{~h}$ to examine restoration of corneal clarity. Light transmittance was quantified before and after glycerol treatment. The absorbance of light at several different wavelengths ranging from 350 
- $700 \mathrm{~nm}$ was determined with a microplate reader (BioTek ${ }^{\mathrm{TM}}$ Synergy HTX), as previously described (12). The transmittance of light was calculated by inverting the absorbance reading. Ultrapure water was used as a baseline control. Images were also recorded of the letter A through the corneas to give a visual representation of the difference in transparency.

\section{Biochemical Analysis}

Corneal buttons were freeze-dried (Christ-Alpha 1-4 LSC Freeze Dryer) and the dry weight was recorded. Corneas were digested in a papain solution $(125 \mu \mathrm{g} / \mathrm{mL})$ in $0.2 \mathrm{M}$ sodium phosphate buffer, $5 \mathrm{mM}$ disodium ethylenediaminetetraacetic acid, $10 \mathrm{mM}$ cysteine hydrochloride, $\mathrm{pH} 6.4$ for $18 \mathrm{~h}$ at $65^{\circ} \mathrm{C}$, as previously described (36). DNA was extracted and purified using a DNeasy Blood and Tissue Kit (Qiagen) and was quantified with a QuantiT ${ }^{\mathrm{TM}}$ PicoGreen ${ }^{\circledR}$ dsDNA Assay Kit (Molecular Probes) according to the manufacturer's instructions. Fluorescence was measured at an excitation wavelength of $480 \mathrm{~nm}$ and an emission wavelength of $520 \mathrm{~nm}$ (Tecan Infinite ${ }^{\circledR} 200$ PRO).

Sulphated glycosaminoglycan (sGAG) content was determined using a 1,9 dimethyl methylene blue (DMMB) assay (Biocolor) according to the manufacturer's protocol . DMMB dye was added to papain-digested samples and mixed thoroughly. The solution was then centrifuged and the supernatant removed. The remaining pellet was resuspended in dissociation dye and the sGAG content was measured by reading the absorbance at $656 \mathrm{~nm}$.

Collagen content was determined using a Sircol ${ }^{\mathrm{TM}}$ soluble collagen assay (Bicolor) according to the manufacturer's protocol. First, freeze-dried corneas were digested at $4{ }^{\circ} \mathrm{C}$ in pepsin extraction reagent $\left(0.1 \mathrm{mg} / \mathrm{mL}\right.$ in $0.5 \mathrm{M}$ acetic acid) for $18 \mathrm{~h}$. Sircol ${ }^{\mathrm{TM}}$ dye reagent was added to pepsin-digested samples and mechanically agitated for $30 \mathrm{~min}$ before being centrifuged. 
The pellet was washed in ice-cold acid salt and centrifuged. The pellet was resuspended in Alkali reagent and collagen content was measured by reading the absorbance of the solution at $555 \mathrm{~nm}$. Values for each assay were calculated by interpolation from a standard curve and normalized to dry weight.

\section{Histological staining}

Scaffolds were fixed in $4 \%$ paraformaldehyde for $18 \mathrm{~h}$. Samples were then dehydrated through a graded series of alcohol from $70 \%$ to $100 \%$ followed by immersion in xylene. Samples were then embedded in paraffin wax and $5 \mu \mathrm{m}$ sections were cut using a microtome (Leica RM2125, Leica Biosystems). Hematoxylin and eosin (H\&E) staining was used to visualize cell presence, while $1 \%$ alcian blue $8 \mathrm{GX}$ solution and picrosirius red staining was performed to examine sGAG and collagen retention, respectively. All samples were imaged using an inverted light microscope coupled to a digital camera (Olympus BX 41, Olympus). For nuclear staining, slides were incubated with 4', 6-diamidino-2-phenylindole (1:500; DAPI) and imaged using an inverted epifluorescent microscope (Olympus IX 71, Olympus).

\section{Mechanical testing}

Unconfined compression experiments were performed. Samples were mechanically tested between two flat impermeable platens connected to 5N load cell (Zwick Z005, Zwick Roell) as previously described (37). Samples were pre-loaded to $10 \%$ strain and allowed to fully relax. The samples were then dynamically loaded at frequencies of $0.1 \mathrm{~Hz}$ and $1 \mathrm{~Hz}$. The compressive modulus was calculated from the first loading cycle while the dynamic modulus was calculated from the average stress and strain amplitude values over 5 cycles.

Transmission Electron Microscopy (TEM) 
Decellularized scaffolds were fixed in $3 \%$ glutaraldehyde in sodium cacodylate buffer solution (0.2M, $\mathrm{pH} 7.2)$ for $18 \mathrm{~h}$ at $4^{\circ} \mathrm{C}$. The scaffolds were post-fixed with $1 \%$ osmium tetroxide in sodium cacodylate buffer solution for $2 \mathrm{~h}$ at room temperature, followed by washing in sodium cacodylate buffer $(0.1 \mathrm{M}, \mathrm{pH} 7.2)$, serial dehydrations in ethanol and washing in propylene oxide (TAAB Laboratories Equipment Ltd.). The scaffolds were embedded in araldite resin (TAAB Laboratories Equipment Ltd.) and sectioned (Leica EM UC6, Leica Biosystems). Ultrathin sections $(90 \mu \mathrm{m})$ were contrasted with uranyl acetate and lead citrate and observed on a transmission electron microscope (FEI Tecnai Biotwin T12), operating at $100 \mathrm{kV}$. Images were recorded using a SIS Megaview digital camera (Olympus). Collagen fibril alignment was quantified using FibrilTool, an Image J (NIH) plug-in, as previously described (38). This plug-in applies circular statistics to analyse variance in tangent direction establishing whether fibrils are well ordered. A score is applied, 0 for no order or isotropic fibrils and 1 for perfectly ordered or anisotropic fibrils. Five distinct regions were chosen in 3 or 4 images for each condition and the anisotropy of collagen fibrils was measured. Fibril diameter was determined using the line drawing tool in Image $\mathbf{J}$ and was measured relative to the length of a $1 \mu \mathrm{m}$ scale bar.

\section{Evaluation of scaffold biocompatibility}

Human keratocyte-derived fibroblast cells were cultured in the presence of decellularized corneas to evaluate biocompatibility. Cells were isolated as previously described (39) in accordance with the Declaration of Helsinki and cultured in low glucose Dulbecco's Modified Eagle's Medium supplemented with $10 \%(v / v)$ foetal bovine serum (FBS; Hyclone), $100 \mathrm{U} / \mathrm{mL}$ penicillin (Gibco); $100 \mu \mathrm{g} / \mathrm{mL}$ streptomycin (Gibco) and $250 \mathrm{ng} / \mathrm{mL}$ amphotericin-B, hereafter called lgDMEM. 1 × $10^{5}$ passage 4 cells were seeded into 6 -well plates (Grenier Bio-One) and allowed to adhere at $37{ }^{\circ} \mathrm{C}$ for $18 \mathrm{~h}$. Corneal buttons were 
placed in 6-well ThinCert ${ }^{\mathrm{TM}}$ culture inserts (Grenier Bio-One) with pore size of $1 \mu \mathrm{m}$ above the cells. All scaffolds were cultured in lgDMEM. Fibroblasts alone formed the control group. In addition, cells were cultured in lgDMEM supplemented with $5 \%$ dextran, termed cells (DM), to examine its effect on cell viability. Cell viability was assessed at 0, 3, 7 and 14 days using a PrestoBlue ${ }^{\mathrm{TM}}$ assay (Molecular Probes) according to the manufacturer's instructions. Results were calculated relative to viability at day 0 .

\section{Statistics}

Statistical analysis was performed using GraphPad Prism software (GraphPad Software Inc., CA, USA). All data are represented as mean \pm standard deviation. The statistical differences were evaluated by either One-Way or Two-Way ANOVA, followed by Bonferroni's multiple comparisons tests. Significance was accepted at a level of $p<0.05$.

\section{Results}

\section{Scaffold swelling and hydration}

All scaffolds underwent a degree of swelling compared to freshly dissected native corneas (Fig. 1A). The average thickness of native corneas was $1.73 \pm 0.23 \mathrm{~mm}$ while the thickness of agitated control $(9.59 \pm 1.07 \mathrm{~mm})$ and detergent only corneas $(3.85 \pm 0.43 \mathrm{~mm})$ were significantly greater (Fig. 1B). Scaffolds decellularized using protocols containing dextran were more comparable to the native corneas with a mean thickness of $2.01 \pm 0.37 \mathrm{~mm}$ for detergent/dextran and $1.94 \pm 0.29 \mathrm{~mm}$ for detergent/dextran wash. Dextran treated corneas were significantly thinner than scaffolds decellularized using detergent only. Percentage swelling was also analysed (Fig. 1C), the mean increase in swelling compared to the native cornea $(100.00 \pm 0.00 \%)$ for each treatment was as follows, $554.80 \pm 61.98 \%$ for agitated control, $222.80 \pm 24.89 \%$ for detergent both significantly greater than the native cornea. 
While detergent/dextran and detergent/dextran wash had increases of $116.39 \pm 21.61 \%$ and $112.34 \pm 16.20 \%$, respectively, with no significant difference to the native tissue.

\section{Light transmittance and corneal transparency}

There was a significant difference in the transparency and light transmittance of native corneas and decellularized corneas immediately after treatment at all the wavelengths analysed (Fig. 2A and B). In all cases, the treated corneas transmitted significantly less light than the native controls. Images recorded of the corneas demonstrate the difference in transparency before and after decellularization treatment. To examine the restoration of corneal clarity the scaffolds were soaked in $100 \%$ glycerol and light transmittance was examined after $18 \mathrm{~h}$ (Fig. 2C). All corneas, except the agitated control, transmitted significantly more light than the native cornea after $18 \mathrm{~h}$. Detergent/dextran and detergent/dextran wash had similar levels of light transmittance to the native cornea that was treated with glycerol (+ Gly), with detergent/dextran showing no significant difference. The images show that all decellularized corneas regained a level of transparency (Fig. 2A).

\section{Residual porcine DNA}

H\&E and DAPI analysis showed cells and nuclei present throughout the cornea before decellularization, while none remained after decellularization treatments (Fig. 3A). Cells were still visible in the agitated control group. Quantification of DNA revealed that irrespective of the decellularization protocol, there was a significant reduction of DNA compared to native corneas (Fig. 3B). The mean DNA content of native and agitated control corneas was $3,335.84 \pm 343.27$ and $1494.78 \pm 100.76 \mathrm{ng} / \mathrm{mg}$ respectively, while the yield from decellularized scaffolds was $120.00 \pm 53.28,124.82 \pm 20.40$, and $111.61 \pm 12.54 \mathrm{ng} / \mathrm{mg}$ 
for detergent, detergent/dextran, and detergent/dextran wash corneas. This technique resulted in an average reduction in DNA of $96 \%$.

\section{sGAG and collagen content following decellularization}

Quantitative results revealed that all decellularization protocols caused a significant reduction in sGAG content compared to native corneas (Fig. 4A). Native and agitated controls contained $7.98 \pm 0.22$ and $6.59 \pm 0.74 \mu \mathrm{g} / \mathrm{mg}$ sGAG respectively. Detergent alone retained $2.14 \pm 0.15 \mu \mathrm{g} / \mathrm{mg}$ of sGAG while detergent/dextran and detergent/dextran wash had levels of $3.87 \pm 0.45$ and $2.92 \pm 0.22 \mu \mathrm{g} / \mathrm{mg}$ respectively. Histological staining with alcian blue demonstrated that all decellularized corneas displayed significantly weaker staining for sGAG (Fig. 4C). The collagen content within the samples was maintained after decellularization with no significant difference from the control samples, all contained $\sim 0.8$ $\mathrm{mg} / \mathrm{mg}$ collagen (Fig. 4B). Histological staining with picrosirius red confirmed these findings (Fig. 4C).

\section{Mechanical properties of decellularized corneas}

To examine the effect of decellularization on the corneal mechanical properties dynamic and compressive loading tests were performed (Fig. 5). The compressive modulus of agitated control $(2.04 \pm 0.94 \mathrm{kPa})$, detergent $(1.86 \pm 0.85 \mathrm{kPa})$ and detergent/dextran wash $(3.65 \pm$ $1.16 \mathrm{kPa})$ corneas was significantly lower than the native cornea $(5.40 \pm 1.18 \mathrm{kPa})$, while detergent/dextran $(5.64 \pm 1.34 \mathrm{kPa})$ had a similar modulus $($ Fig. 5A). The decellularization process caused a significant reduction in the dynamic modulus of the corneal stroma at 0.1 $\mathrm{Hz}$ of agitated control $(3.83 \pm 1.99 \mathrm{kPa})$ and detergent $(6.71 \pm 2.49 \mathrm{kPa})$ corneas compared to the native tissue $(15.20 \pm 4.38 \mathrm{kPa})$, while detergent/dextran wash was not significantly different at $14.90 \pm 3.66 \mathrm{kPa}$ (Fig. 5B). In contrast, detergent/dextran displayed a 
significantly higher modulus of $21.70 \pm 2.45 \mathrm{kPa}$. There was a similar trend for $1 \mathrm{~Hz}$ dynamic modulus with agitated control $(4.09 \pm 2.55 \mathrm{kPa})$ and detergent $(4.83 \pm 1.37 \mathrm{kPa})$ being significantly lower than the native control $(17.50 \pm 5.13 \mathrm{kPa})$, while detergent/dextran wash displayed similar properties with a modulus of $19.00 \pm 4.97 \mathrm{kPa}$ (Fig. 5C). The dynamic modulus at $1 \mathrm{~Hz}$ for detergent/dextran was again significantly greater than the native cornea at $25.94 \pm 2.88 \mathrm{kPa}$.

\section{Ultrastructure of the cornea and collagen fibril alignment}

Collagen fibril orientation and disruption to the corneal architecture following decellularization was examined using TEM (Fig. 6). The typical orthogonal fibril arrangement was evident in the native cornea, with collagen fibrils tightly packed within the tissue. The agitated control had similar structure, although the collagen bundles were more widely spaced due to corneal swelling. Decellularization with detergents alone caused a loss of collagen fibril alignment. The use of dextran revealed a more uniform arrangement of fibrils, with detergent/dextran most resembling the native cornea. Quantification of fibril alignment demonstrated a significant reduction in fibril alignment for detergent $(0.14 \pm 0.01)$ and detergent/dextran wash $(0.15 \pm 0.06)$ groups compared to the native control $(0.24 \pm 0.02)$ (Fig. 7A). Agitated control and detergent/dextran maintained similar fibril alignment to fresh stromal tissue with an anisotropy of $0.18 \pm 0.04$ and $0.22 \pm 0.03$ respectively. When fibril diameter was quantified (Fig. 7B), agitated control $(28.78 \pm 1.68 \mathrm{~nm})$ and detergent/dextran $(28.33 \pm 1.23 \mathrm{~nm})$ corneas had similar diameters compared to the native control $(30.98 \pm 2.46$ $\mathrm{nm})$. However, detergent $(25.58 \pm 1.15 \mathrm{~nm})$ and detergent/dextran wash $(26.41 \pm 2.36 \mathrm{~nm})$ displayed a small but significant reduction in diameter.

\section{Scaffold biocompatibility}


Cell viability assays demonstrated a small but significant increase in cell proliferation for all groups, except cells only and cells (DM), over the culture period of 14 days compared to day

0 (Fig. 8). There was an initial surge in cell proliferation for the first three days in the presence of corneal tissue. There was no significant difference in cell proliferation when comparing detergent and detergent/dextran to the agitated control at day 3, while detergent/dextran wash had significantly enhanced proliferation. By day 7 there was no significant difference between agitated control and detergent/dextran, however both detergent and detergent/dextran wash demonstrated significantly greater proliferation. At day 14 cell proliferation for both dextran treated corneas was similar to the agitated control, while that for detergent was significantly greater. Despite the significance observed the values for cell viability for each cornea treatment were in a similar range to each other, between $\sim 105-115$ $\%$ cell viability over 14 days relative to day 0 . Cells cultured in the presence of dextran showed a significant increase in cell proliferation at day 3 compared to cells alone, this continued to day 7 after which the cells behaved as in normal $\operatorname{lgDMEM}$ with no significant difference between the two by day 14 .

\section{Discussion}

Decellularized scaffolds require that cellular and nuclear components of the tissue be removed while the composition and structure of the ECM are maintained $(18,20)$. This approach to biologic scaffold generation has been successful with a variety of tissue types and the resultant acellular ECM has been examined in both pre-clinical studies and human clinical applications $(22,40-42)$. One problem associated with corneal decellularization is control of tissue hydration (43-45). During an effective decellularization process the endothelium of the cornea is completely removed. The corneal endothelium is essential for maintaining human vision by regulating the hydration state of the stroma by way of $\mathrm{Na}+\mathrm{K}+-$ 


\begin{abstract}
ATPase pump functioning (46-48). Once the cornea is denuded of the endothelium it undergoes extensive swelling (43-45). In this study, the use of dextran during decellularization was investigated to prevent swelling and maintain the discrete and complex features of the corneal ECM.
\end{abstract}

Dextran is routinely used to maintain the hydration state of corneas in storage via colloid osmotic pressure (34). Prior to keratoplasty, a concentration of 5\% dextran is routinely used to maintain graft thickness $(35,49,50)$. The addition of dextran during corneal decellularization has only been previously used in conjunction with ultrahigh hydrostatic pressure (HHP) $(43,44)$. The authors in these studies used dextran at a concentration of $3.5 \%$, although no rationale was provided for the use of this concentration. Sasaki et al. (2009) used dextran prior to decellularization to maintain the native corneas dimensions, however the effect of dextran was not described. Hashimoto et al. (2010) used dextran to prevent swelling during the washing step to avoid the swelling observed in during washing without dextran. Dextran was not used during the decellularization procedure itself. The examination of the effect of dextran was limited to swelling analysis that demonstrated a significant reduction in corneal thickness. There was no direct comparison of the addition of dextran to those without dextran in the decellularization process for other parameters analysed. The primary emphasis of these studies was on decellularization with HHP and not the addition of dextran. However, this decellularization method is limited by the need for expensive specialized equipment capable of applying pressures up to $1 \mathrm{GPa}$ to the corneas (18). Our study used relatively inexpensive detergents and enzymes that are highly effective at removing cells and cellular debris. The addition of dextran during decellularization was successful in regulating scaffold water content. Corneas decellularized or washed in the presence of dextran displayed a marked decrease in swelling compared to those with 
detergents and nucleases alone, with dimensions remaining similar to the native cornea, consistent with HHP studies. The extensive swelling observed for the agitated control can be attributed to the physiological $\mathrm{pH}, \mathrm{pH} 7.40$, of the PBS solution used. The isoelectric point of the cornea is considered to be close to $\mathrm{pH} 4$ and the stroma undergoes hydration and swelling when moving away form this value $(51,52)$. The decellularization solutions used in this study were determined to be $\mathrm{pH} 4.00$ and $\mathrm{pH} 4.07$ for detergent and detergent/dextran, respectively. This suggests that dextran serves as an adjunct to the standard decellularization solution to prevent significant swelling.

The concentrations of detergents in our study, 0.5\% SDS and 1\% Triton-X 100, have previously been used to effectively decellularize the cornea $(28,53-55)$. The use of detergents and nucleases for decellularization was effective in removing cellular components from the cornea and these results are consistent with other reports $(23,53,54,56)$. The effectiveness of this method is generally considered to be due to adequate disruption of the ECM enabling effective infiltration of decellularization factors into the scaffold (57). However, the addition of dextran restricts corneal swelling, minimizing ECM disruption. Despite this the decellularizing agents were able to infiltrate the scaffold effectively and remove cellular components.

Biologic ECM scaffolds are an attractive choice for tissue engineering and regenerative applications since the structure and composition of ECM is similar between species $(57,58)$. Maintenance of these features will enhance the functionality of the scaffold although any protocol aimed at complete cellular removal will result in some ECM disruption $(57,59,60)$. Furthermore, the ECM contains intrinsic biological signals, including growth factors and cytokines, that play an important role in the maintenance of cell migration, proliferation and 
phenotype $(19,31,61)$, and can affect the host remodelling response following in vivo implantation $(58,59,61,62)$. The GAG content after decellularization provides a useful indication as to the extent that biochemical cues and ECM components have been lost from the cornea. The concentration of GAGs was reduced in corneas decellularized using detergents even with the addition of dextran. Optimization of the concentration of detergents may improve the retention of GAGs in the ECM.

In addition to biochemical cues, the ultrastructural and topographical characteristics of the tissue play an important role in modulating cell behaviour (62). In the case of the cornea, maintenance of collagen fibril alignment is essential for transparency of the replacement tissue. The predominant corneal collagen is collagen type I $(27,63)$. The uniform diameter and high level of lateral order of these fibrils gives the cornea its transparency (26). A simple method to evaluate the maintenance of this architecture, that is often employed, is to soak corneas in glycerol after decellularization $(20,56,64)$ and evaluate changes macroscopically and by measuring light transmittance. Transparency was enhanced in all corneas after soaking in glycerol, however the dextran treated corneas had a similar level of light transmittance to the native cornea that was also treated in glycerol suggesting that the histoarchitecture of the stroma was maintained for these groups, similar results were obtained in the HHP studies using dextran. In addition, collagen content was maintained in all groups regardless of the decellularization method used. This is in agreement with previous decellularization studies carried out on annulus fibrosis tissue (65), tendon (66) and articular cartilage (67). Ultrastructural maintenance with TEM analysis demonstrated that scaffolds treated with detergent/dextran most closely resembled the native cornea. Our data showed that detergent alone had significantly enhanced light transmittance after glycerol treatment well above the level of the native tissue and greater than dextran treated corneas, however 
TEM analysis confirmed significant disruption to the collagen architecture. It has been demonstrated that glycerol can reduce light scattering and improve the optical transmittance of scaffolds (68), however in this case glycerol could have disguised the damage caused to the cornea by the detergent only decellularization process. Fibril diameter plays an important role in corneal transparency. The corneal stroma consists of uniformly aligned collagen fibrils of $25-35 \mathrm{~nm}$ in diameter $(69,70)$. In this study, fibril diameter for treated samples ranged from 25.58 - $28.78 \mathrm{~nm}$ consistent with normal stromal diameters, despite the decrease observed for detergent and detergent/dextran wash groups. Collagen fibrils in the normal cornea are weak at scattering light as their diameter is smaller than the wavelength of light resulting in a transparent tissue (71). Collagen fibril diameter is increased in corneal wound and scar tissue resulting in increased light scattering (72, 73). Huang and Meek (1999) suggested that fibril diameter doesn't change much over a range of hydrations, this is consistent with the data presented in this study that there was little change in fibril diameter and thusly fibril diameter has little impact on light transmittance in this study.

The corneal mechanical properties can be ascribed to the gross arrangement of collagen fibrils within multiple lamellae that lie approximately parallel to the tissue surface (26). An engineered corneal replacement has to withstand suturing during surgery (74) in addition to membrane stresses caused by intraocular pressure and external forces such as eyelid pressure (30). Many strategies to engineer replacement tissue involve the use of soft hydrogels that have mechanical properties inferior to the native tissue (75). The elastic modulus of the bulk cornea has previously been estimated by several different methods resulting in a wide range of values, $5 \mathrm{kPa}$ to $20 \mathrm{MPa}(30,76-79)$. The modulus obtained depends on the testing method, testing conditions and orientation of the cornea with respect to applied stress (79). Hatami-Marbini et al. performed out-of-plane compressive testing on corneal tissue and 
found the compressive modulus could range between 0.6 and $13.8 \mathrm{kPa}$, and that the modulus increases with increasing strain $(30,78)$, consistent with our findings. Corneas treated with detergents alone had inferior mechanical properties compared to native corneas. This result correlates with a previous study that showed decellularization using SDS could reduce the ultimate tensile strength of the cornea from 4.5 MPa to 2.5 MPa (28). The addition of dextran enabled the decellularized scaffolds to retain the corneas mechanical characteristics. However, corneas treated with detergent/dextran resulted in an increased dynamic modulus ranging from $21-25 \mathrm{kPa}$ compared to $15-17 \mathrm{kPa}$ for the native corneas.. Despite this increase the moduli determined are well within the limits of the normal cornea that have been determined previously in the literature. If a cornea is too weak it will be unusable as it will not be able to withstand the physiological loads experienced by the cornea. A cornea that is too stiff, however, can be detrimental to the functionality of a corneal replacement. Rigid artificial implants and keratoprostheses have experienced complications post-implantation including glaucoma, extrusion and rejection (80).

The capacity of the scaffold to support host cells is essential when considering tissueengineering applications $(18,25,54)$. Viability assays revealed that cells remained viable in the presence of decellularized corneas and may even enhance cell proliferation compared to cells alone. It has been demonstrated that extract from the corneal stroma contains active factors that can enhance keratocyte proliferation (81), which supports our findings. These results suggest that detergents added during the decellularization process that would have a detrimental effect on the cell viability are effectively removed by the washing process.

\section{Conclusion}


It has been demonstrated that the addition of dextran can be used to control swelling and reduce structural ECM damage during corneal decellularization. These findings should enable researchers who are developing decellularization protocols to significantly refine their technique and produce decellularized scaffolds that closely resemble the structure and composition of the native human cornea.

\section{Acknowledgments}

Research conducted with the financial support of Science Foundation Ireland and MarieCurie Action COFUND grant number: 11/SIRG/B2104; EPSRC Engineering, Tissue Engineering and Regenerative Medicine (E-TERM), grant number: EP/I017801/1 and COST Action BM-1302, Joining Forces in Corneal Regeneration Research, as part of a short-term scientific mission. Technical assistance and expertise from Denise Mclean, in the Advanced Microscopy Unit (School of Life Sciences, University of Nottingham), is very much appreciated. 


\section{References}

1. Resnikoff, S., Pascolini, D., Mariotti, S.P., and Pokharel, G.P. Global magnitude of visual impairment caused by uncorrected refractive errors in 2004. Bull World Health Organ 86, 63, 2008.

2. Pascolini, D., and Mariotti, S.P. Global estimates of visual impairment: 2010. Br J Ophthalmol 96, 614, 2012.

3. George, A.J., and Larkin, D.F. Corneal transplantation: the forgotten graft. Am J Transplant 4, 678, 2004.

4. Hager, J.L., Phillips, D.L., Goins, K.M., Kitzmann, A.S., Greiner, M.A., Cohen, A.W., Welder, J.D., and Wagoner, M.D. Boston type 1 keratoprosthesis for failed keratoplasty. Int Ophthalmol, 1, 2015.

5. Alio, J.L., Abdelghany, A.A., Abu-Mustafa, S.K., and Zein, G. A new epidescemetic keratoprosthesis: pilot investigation and proof of concept of a new alternative solution for corneal blindness. Br J Ophthalmol 99, 1483, 2015.

6. Zhiqiang, P., Cun, S., Ying, J., Ningli, W., and Li, W. WZS-pig is a potential donor alternative in corneal xenotransplantation. Xenotransplantation 14, 603, 2007.

7. van Essen, T.H., Lin, C.C., Hussain, A.K., Maas, S., Lai, H.J., Linnartz, H., van den Berg, T.J., Salvatori, D.C., Luyten, G.P., and Jager, M.J. A fish scale-derived collagen matrix as artificial cornea in rats: properties and potential. Invest Ophthalmol Vis Sci 54, 3224, 2013.

8. Choi, H.J., Kim, M.K., Lee, H.J., Ko, J.H., Jeong, S.H., Lee, J.I., Oh, B.C., Kang, H.J., and Wee, W.R. Efficacy of pig-to-rhesus lamellar corneal xenotransplantation. Invest Ophthalmol Vis Sci 52, 6643, 2011.

9. Fagerholm, P., Lagali, N.S., Merrett, K., Jackson, W.B., Munger, R., Liu, Y., Polarek, J.W., Soderqvist, M., and Griffith, M. A biosynthetic alternative to human donor tissue for 
inducing corneal regeneration: 24-month follow-up of a phase 1 clinical study. Sci Transl Med 2, 46ra61, 2010.

10. Hicks, C.R., Crawford, G.J., Lou, X., Tan, D.T., Snibson, G.R., Sutton, G., Downie, N., Werner, L., Chirila, T.V., and Constable, I.J. Corneal replacement using a synthetic hydrogel cornea, AlphaCor $^{\mathrm{TM}}$ : device, preliminary outcomes and complications. Eye 17, 385, 2003.

11. Fagerholm, P., Lagali, N.S., Ong, J.A., Merrett, K., Jackson, W.B., Polarek, J.W., Suuronen, E.J., Liu, Y., Brunette, I., and Griffith, M. Stable corneal regeneration four years after implantation of a cell-free recombinant human collagen scaffold. Biomaterials 35, 2420, 2014.

12. Ahearne, M., and Lynch, A.P. Early Observation of Extracellular Matrix-Derived Hydrogels for Corneal Stroma Regeneration. Tissue Eng Part C Methods 21, 1059, 2015.

13. Ionescu, A.-M., Alaminos, M., Cardona, J.d.1.C., García-López Durán, J.d.D., GonzálezAndrades, M., Ghinea, R., Campos, A., Hita, E., and Pérez, M.d.M. Investigating a novel nanostructured fibrin-agarose biomaterial for human cornea tissue engineering: Rheological properties. J Mech Behav Biomed Mater 4, 1963, 2011.

14. Alaminos, M., Del Carmen Sanchez-Quevedo, M., Munoz-Avila, J.I., Serrano, D., Medialdea, S., Carreras, I., and Campos, A. Construction of a complete rabbit cornea substitute using a fibrin-agarose scaffold. Invest Ophthalmol Vis Sci 47, 3311, 2006.

15. Wu, J., Rnjak-Kovacina, J., Du, Y., Funderburgh, M.L., Kaplan, D.L., and Funderburgh, J.L. Corneal stromal bioequivalents secreted on patterned silk substrates. Biomaterials 35, 3744, 2014.

16. Mimura, T., Amano, S., Yokoo, S., Uchida, S., Yamagami, S., Usui, T., Kimura, Y., and Tabata, Y. Tissue engineering of corneal stroma with rabbit fibroblast precursors and gelatin hydrogels. Mol Vis 14, 1819, 2008. 
17. Wilson, S.L., Wimpenny, I., Ahearne, M., Rauz, S., El Haj, A.J., and Yang, Y. Chemical and topographical effects on cell differentiation and matrix elasticity in a corneal stromal layer model. Adv Funct Mater 22, 3641, 2012.

18. Lynch, A.P., and Ahearne, M. Strategies for developing decellularized corneal scaffolds. Exp Eye Res 108, 42, 2013.

19. Badylak, S.F. Xenogeneic extracellular matrix as a scaffold for tissue reconstruction. Transpl Immunol 12, 367, 2004.

20. Murphy, S.V., and Atala, A. Organ engineering - combining stem cells, biomaterials, and bioreactors to produce bioengineered organs for transplantation. Bioessays 35, 163, 2012.

21. Dellgren, G., Eriksson, M., Brodin, L.A., and Radegran, K. The extended Biocor stentless aortic bioprosthesis. Early clinical experience. Scand Cardiovasc J 33, 259, 1999.

22. Harper, C. Permacol: clinical experience with a new biomaterial. Hosp Med 62, 90, 2001.

23. Diao, J.M., Pang, X., Qiu, Y., Miao, Y., Yu, M.M., and Fan, T.J. Construction of a human corneal stromal equivalent with non-transfected human corneal stromal cells and acellular porcine corneal stromata. Exp Eye Res 132, 216, 2015.

24. Yoeruek, E., Bayyoud, T., Maurus, C., Hofmann, J., Spitzer, M.S., Bartz-Schmidt, K.-U., and Szurman, P. Decellularization of porcine corneas and repopulation with human corneal cells for tissue-engineered xenografts. Acta Ophthalmol 90, 125, 2012.

25. Gonzalez-Andrades, M., de la Cruz Cardona, J., Ionescu, A.M., Campos, A., Del Mar Perez, M., and Alaminos, M. Generation of bioengineered corneas with decellularized xenografts and human keratocytes. Invest Ophthalmol Vis Sci 52, 215, 2011.

26. Boote, C., Kamma-Lorger, C.S., Hayes, S., Harris, J., Burghammer, M., Hiller, J., Terrill, N.J., and Meek, K.M. Quantification of collagen organization in the peripheral human cornea at micron-scale resolution. Biophys J 101, 33, 2011. 
27. Meek, K.M., and Boote, C. The organization of collagen in the corneal stroma. Exp Eye Res 78, 503, 2004.

28. Du, L., Wu, X., Pang, K., and Yang, Y. Histological evaluation and biomechanical characterisation of an acellular porcine cornea scaffold. Br J Ophthalmol 95, 410, 2011.

29. Bentley, E., Murphy, C.J., Li, F., Carlsson, D.J., and Griffith, M. Biosynthetic corneal substitute implantation in dogs. Cornea 29, 910, 2010.

30. Hatami-Marbini, H., and Etebu, E. An experimental and theoretical analysis of unconfined compression of corneal stroma. J Biomech 46, 1752, 2013.

31. Wilson, S.L., Sidney, L.E., Dunphy, S.E., Rose, J.B., and Hopkinson, A. Keeping an eye on decellularized corneas: a review of methods, characterization and applications. $\mathbf{J}$ Func Biomater 4, 114, 2013.

32. Pels, L. Organ culture: the method of choice for preservation of human donor corneas. $\mathrm{Br}$ J Ophthalmol 81, 523, 1997.

33. Kling, S., and Marcos, S. Effect of hydration state and storage media on corneal biomechanical response from in vitro inflation tests. J Refract Surg 29, 490, 2013.

34. Jablonski-Stiemke, M.M., and Edelhauser, H.F. Storage of human corneas in dextran and chondroitin sulfate-based corneal storage medium: changes in stromal free sodium. Arch Ophthalmol 116, 627, 1998.

35. Nejepinska, J., Juklova, K., and Jirsova, K. Organ culture, but not hypothermic storage, facilitates the repair of the corneal endothelium following mechanical damage. Acta Ophthalmol 88, 413, 2010.

36. Vavken, P., Joshi, S., and Murray, M.M. TRITON-X is most effective among three decellularization agents for ACL tissue engineering. J Orthop Res 27, 1612, 2009. 
37. Buckley, C.T., Thorpe, S.D., O'Brien, F.J., Robinson, A.J., and Kelly, D.J. The effect of concentration, thermal history and cell seeding density on the initial mechanical properties of agarose hydrogels. J Mech Behav Biomed Mater 2, 512, 2009.

38. Boudaoud, A., Burian, A., Borowska-Wykręt, D., Uyttewaal, M., Wrzalik, R., Kwiatkowska, D., and Hamant, O. FibrilTool, an ImageJ plug-in to quantify fibrillar structures in raw microscopy images. Nat Protocols 9, 457, 2014.

39. Wilson, S.L., Yang, Y., and El Haj, A.J. Corneal stromal cell plasticity: in vitro regulation of cell phenotype through cell-cell interactions in a three-dimensional model. Tissue Eng Part A 20, 225, 2014.

40. Chen, F., Yoo, J.J., and Atala, A. Acellular collagen matrix as a possible "off the shelf" biomaterial for urethral repair. Urology 54, 407, 1999.

41. Kolker, A.R., Brown, D.J., Redstone, J.S., Scarpinato, V.M., and Wallack, M.K. Multilayer reconstruction of abdominal wall defects with acellular dermal allograft (AlloDerm) and component separation. Ann Plast Surg 55, 36, 2005.

42. Metcalf, M.H., Savoie Iii, F.H., and Kellum, B. Surgical technique for xenograft (SIS) augmentation of rotator-cuff repairs. Oper Tech Orthop 12, 204, 2002.

43. Hashimoto, Y., Funamoto, S., Sasaki, S., Honda, T., Hattori, S., Nam, K., Kimura, T., Mochizuki, M., Fujisato, T., Kobayashi, H., and Kishida, A. Preparation and characterization of decellularized cornea using high-hydrostatic pressurization for corneal tissue engineering. Biomaterials 31, 3941, 2010.

44. Sasaki, S., Funamoto, S., Hashimoto, Y., Kimura, T., Honda, T., Hattori, S., Kobayashi, H., Kishida, A., and Mochizuki, M. In vivo evaluation of a novel scaffold for artificial corneas prepared by using ultrahigh hydrostatic pressure to decellularize porcine corneas. Mol Vis 15, 2022, 2009. 
45. Lee, W., Miyagawa, Y., Long, C., Cooper, D.K., and Hara, H. A comparison of three methods of decellularization of pig corneas to reduce immunogenicity. Int J Ophthalmol 7, $587,2014$.

46. Ju, C., Gao, L., Wu, X., and Pang, K. A human corneal endothelium equivalent constructed with acellular porcine corneal matrix. Indian J Med Res 135, 887, 2012.

47. Proulx, S., Audet, C., Uwamaliya, J., Deschambeault, A., Carrier, P., Giasson, C.J., Brunette, I., and Germain, L. Tissue engineering of feline corneal endothelium using a devitalized human cornea as carrier. Tissue Eng Part A 15, 1709, 2009.

48. Hatou, S., Yamada, M., Akune, Y., Mochizuki, H., Shiraishi, A., Joko, T., Nishida, T., and Tsubota, K. Role of insulin in regulation of Na+-/K+-dependent ATPase activity and pump function in corneal endothelial cells. Invest Ophthalmol Vis Sci 51, 3935, 2010.

49. Pogorelov, P., Cursiefen, C., Bachmann, B.O., and Kruse, F.E. Changes in donor corneal lenticule thickness after Descemet's stripping automated endothelial keratoplasty (DSAEK) with organ-cultured corneas. Br J Ophthalmol 93, 825, 2009.

50. Pels, E., Beele, H., and Claerhout, I. Eye bank issues: II. Preservation techniques: warm versus cold storage. Int Ophthalmol 28, 155, 2008.

51. Huang, Y., and Meek, K.M. Swelling studies on the cornea and sclera: the effects of pH and ionic strength. Biophys J 77, 1655, 1999.

52. Elliott, G.F., Goodfellow, J.M., and Woolgar, A.E. Swelling studies of bovine corneal stroma without bounding membranes. J Physiol 298, 453, 1980.

53. Du, L., and Wu, X. Development and Characterization of a Full-Thickness Acellular Porcine Cornea Matrix for Tissue Engineering. Artif Organs 35, 691, 2011.

54. Shafiq, M.A., Gemeinhart, R.A., Yue, B.Y., and Djalilian, A.R. Decellularized human cornea for reconstructing the corneal epithelium and anterior stroma. Tissue Eng Part C Methods 18, 340, 2012. 
55. Fu, Y., Fan, X., Chen, P., Shao, C., and Lu, W. Reconstruction of a tissue-engineered cornea with porcine corneal acellular matrix as the scaffold. Cells Tissues Organs 191, 193, 2010.

56. Bayyoud, T., Thaler, S., Hofmann, J., Maurus, C., Spitzer, M.S., Bartz-Schmidt, K.-U., Szurman, P., and Yoeruek, E. Decellularized Bovine Corneal Posterior Lamellae as Carrier Matrix for Cultivated Human Corneal Endothelial Cells. Curr Eye Res 37, 179, 2012.

57. Gilbert, T.W., Sellaro, T.L., and Badylak, S.F. Decellularization of tissues and organs. Biomaterials 27, 3675, 2006.

58. Gilbert, T.W. Strategies for tissue and organ decellularization. J Cell Biochem 113, 2217, 2012.

59. Keane, T.J., Swinehart, I.T., and Badylak, S.F. Methods of tissue decellularization used for preparation of biologic scaffolds and in vivo relevance. Methods 85, 252015.

60. Ponce Márquez, S., Martínez, V.S., McIntosh Ambrose, W., Wang, J., Gantxegui, N.G., Schein, O., and Elisseeff, J. Decellularization of bovine corneas for tissue engineering applications. Acta Biomater 5, 1839, 2009.

61. Crapo, P.M., Gilbert, T.W., and Badylak, S.F. An overview of tissue and whole organ decellularization processes. Biomaterials 32, 3233, 2011.

62. Badylak, S.F., Taylor, D., and Uygun, K. Whole-organ tissue engineering: decellularization and recellularization of three-dimensional matrix scaffolds. Annu Rev Biomed Eng 13, 27, 2011.

63. Hassell, J.R., and Birk, D.E. The molecular basis of corneal transparency. Exp Eye Res 91, 326, 2010.

64. Yoeruek, E., Bayyoud, T., Maurus, C., Hofmann, J., Spitzer, M.S., Bartz-Schmidt, K.U., and Szurman, P. Reconstruction of corneal stroma with decellularized porcine xenografts in a rabbit model. Acta Ophthalmol 90, e206, 2012. 
65. Xu, H., Xu, B., Yang, Q., Li, X., Ma, X., Xia, Q., Zhang, Y., Zhang, C., Wu, Y., and Zhang, Y. Comparison of decellularization protocols for preparing a decellularized porcine annulus fibrosus scaffold. PloS one 9, e86723, 2014.

66. Youngstrom, D.W., Barrett, J.G., Jose, R.R., and Kaplan, D.L. Functional characterization of detergent-decellularized equine tendon extracellular matrix for tissue engineering applications. PloS one 8, e64151, 2013.

67. Elder, B.D., Kim, D.H., and Athanasiou, K.A. Developing an articular cartilage decellularization process toward facet joint cartilage replacement. Neurosurgery 66, 722, 2010.

68. Zhao, S., Shen, Z., Wang, J., Li, X., Zeng, Y., Wang, B., He, Y., and Du, Y. Glycerolmediated nanostructure modification leading to improved transparency of porous polymeric scaffolds for high performance 3D cell imaging. Biomacromolecules 15, 2521, 2014.

69. Ghezzi, C.E., Rnjak-Kovacina, J., and Kaplan, D.L. Corneal tissue engineering: recent advances and future perspectives. Tissue Eng Part B Rev 21, 278, 2015.

70. Muthusubramaniam, L., Peng, L., Zaitseva, T., Paukshto, M., Martin, G.R., and Desai, T.A. Collagen fibril diameter and alignment promote the quiescent keratocyte phenotype. J Biomed Mater Res A 100, 613, 2012.

71. Ruberti, J.W., and Zieske, J.D. Prelude to corneal tissue engineering - gaining control of collagen organization. Prog Retin Eye Res 27, 549, 2008.

72. Kamma-Lorger, C.S., Boote, C., Hayes, S., Albon, J., Boulton, M.E., and Meek, K.M. Collagen ultrastructural changes during stromal wound healing in organ cultured bovine corneas. Exp Eye Res 88, 953, 2009.

73. McCally, R.L., Freund, D.E., Zorn, A., Bonney-Ray, J., Grebe, R., de la Cruz, Z., and Green, W.R. Light-scattering and ultrastructure of healed penetrating corneal wounds. Invest Ophthalmol Vis Sci 48, 157, 2007. 
74. Long, K., Liu, Y., Li, W., Wang, L., Liu, S., Wang, Y., Wang, Z., and Ren, L. Improving the mechanical properties of collagen-based membranes using silk fibroin for corneal tissue engineering. J Biomed Mater Res A 103, 1159, 2015.

75. Zhu, J., and Marchant, R.E. Design properties of hydrogel tissue-engineering scaffolds. Expert Rev Med Devices 8, 607, 2011.

76. Asejczyk-Widlicka, M., Srodka, D.W., Kasprzak, H., and Pierscionek, B.K. Modelling the elastic properties of the anterior eye and their contribution to maintenance of image quality: the role of the limbus. Eye (Lond) 21, 1087, 2007.

77. Boschetti, F., Triacca, V., Spinelli, L., and Pandolfi, A. Mechanical characterization of porcine corneas. J Biomech Eng 134, 031003, 2012.

78. Hatami-Marbini, H., and Etebu, E. Rate dependent biomechanical properties of corneal stroma in unconfined compression. Biorheology 50, 133, 2013.

79. Last, J.A., Liliensiek, S.J., Nealey, P.F., and Murphy, C.J. Determining the mechanical properties of human corneal basement membranes with atomic force microscopy. J Struct Biol 167, 19, 2009.

80. Myung, D., Duhamel, P.E., Cochran, J.R., Noolandi, J., Ta, C.N., and Frank, C.W. Development of hydrogel-based keratoprostheses: a materials perspective. Biotechnol Prog 24, 735, 2008.

81. Musselmann, K., Kane, B.P., and Hassell, J.R. Isolation of a putative keratocyte activating factor from the corneal stroma. Exp Eye Res 77, 273, 2003.

\section{Figures}



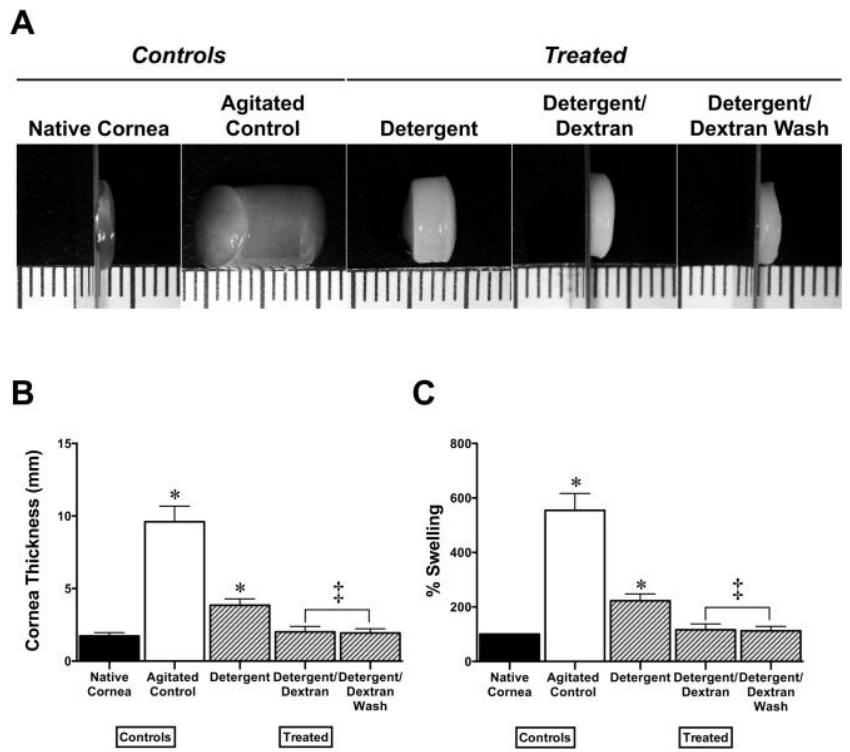

Figure 1: (A) Macroscopic swelling analysis of decellularized corneas. (B) Mean thickness and (C) percentage swelling following decellularization $(\mathrm{n}=12 \pm$ standard deviation, * represents significant difference compared to native cornea, $\$$ represents significant difference compared to detergent, $p<0.05)$. 

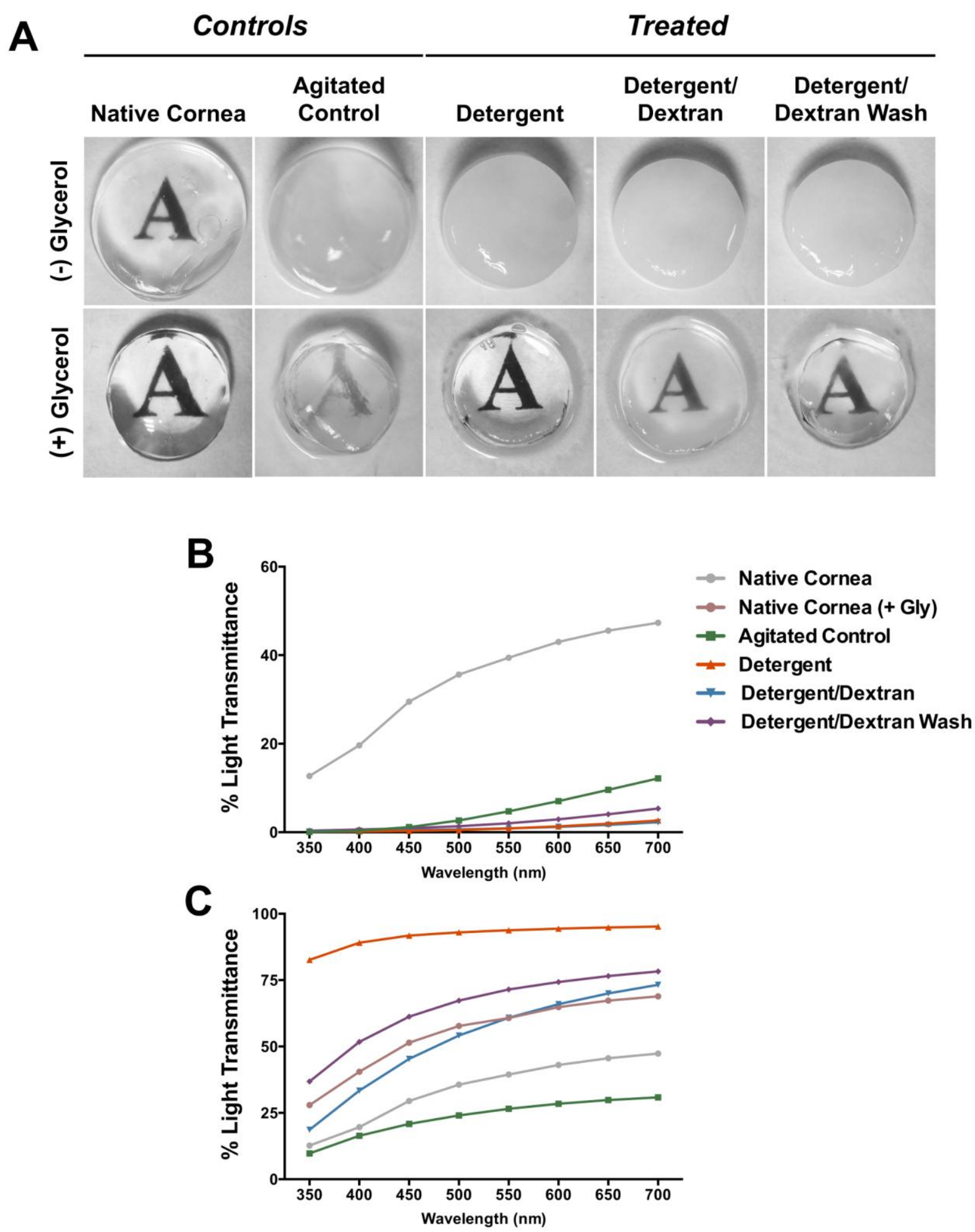

Figure 2: (A) Macroscopic evaluation of tissue transparency following decellularization, with and without glycerol treatment. Percentage of light transmitted through corneas (B) 
before glycerol treatment, $(\mathrm{C})$ after soaking in $100 \%$ glycerol for $18 \mathrm{~h}$ at 350 to $700 \mathrm{~nm}(n=$ 8). 
A

Controls

Treated

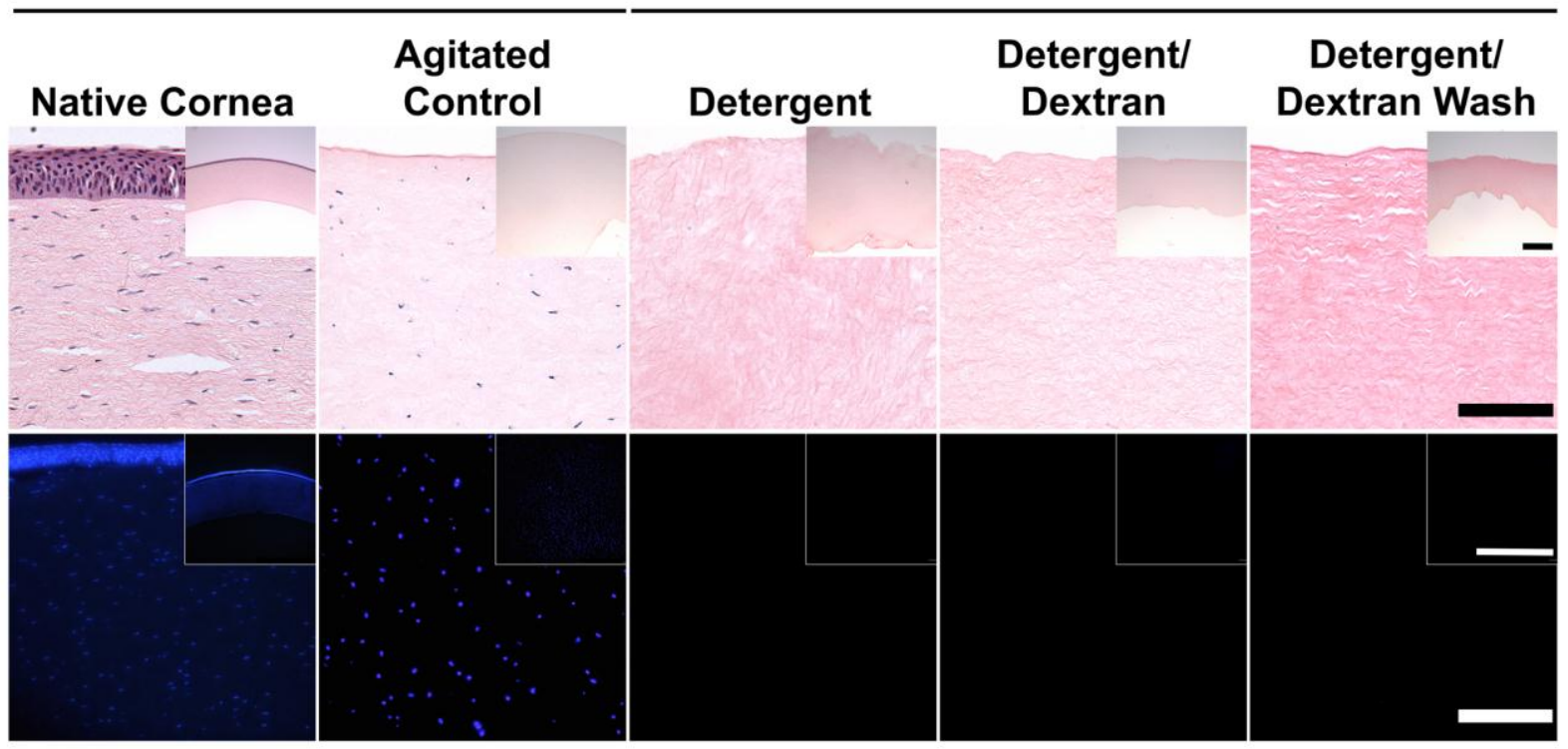

B

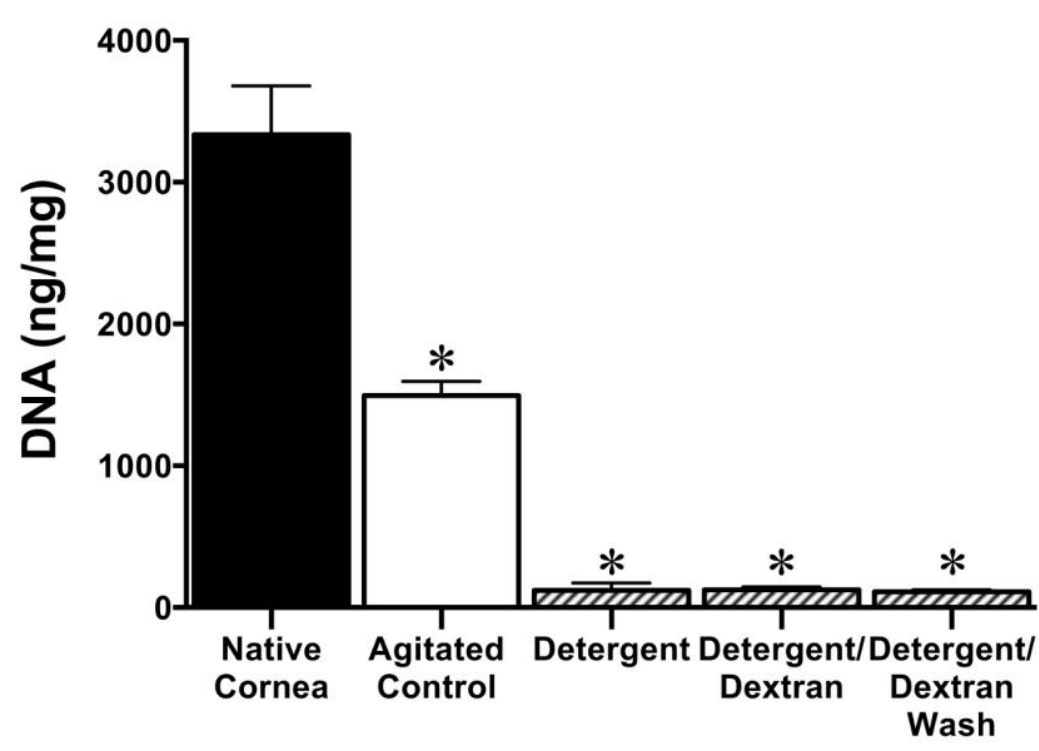

Controls

Treated

Figure 3: (A) Haematoxylin and Eosin stained corneal sections (top panel) scale bar $=100$ $\mu \mathrm{m}$ and $1 \mu \mathrm{m}$ (insert); DAPI stained corneal sections (bottom panel) scale bar $200 \mu \mathrm{m}$ and 2 mm (insert). (B) Quantification of DNA from fresh and decellularized corneal tissue $(n=3, \pm$ standard deviation, $*$ represents significant difference compared to native cornea, $p<0.05)$. 
A
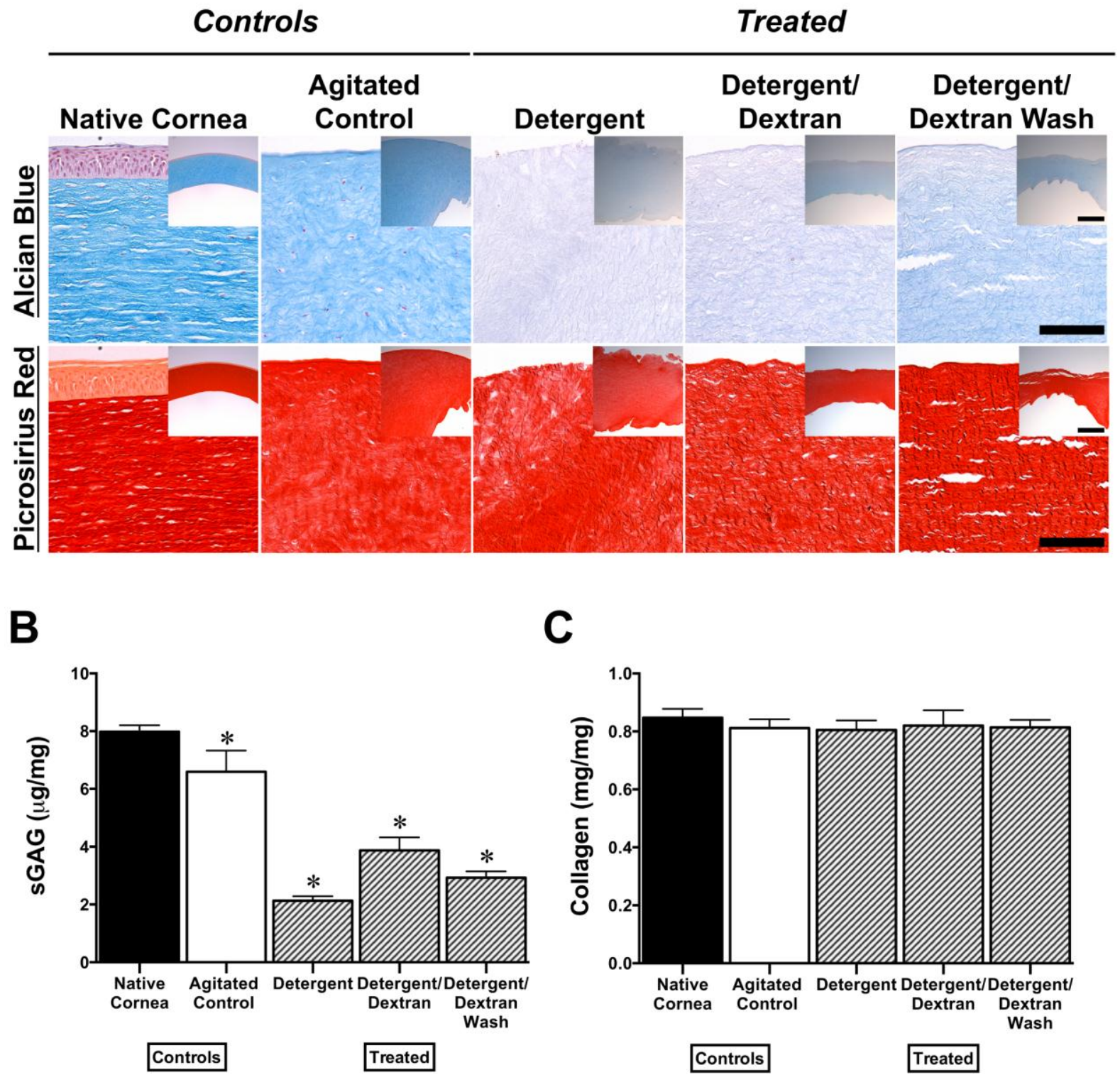

Figure 4: (A) Alcian blue and picrosirius red stained corneal sections, for sGAG and collagen respectively, scale bar $=100 \mu \mathrm{m}$ and $1 \mathrm{~mm}$ (insert). (B) Quantification of sGAG and (C) collagen from fresh and decellularized corneal tissue $(n=3, \pm$ standard deviation, * represents significant difference compared to native corneas, $p<0.05)$. 
Page 34 of 39 
Page 35 of 39

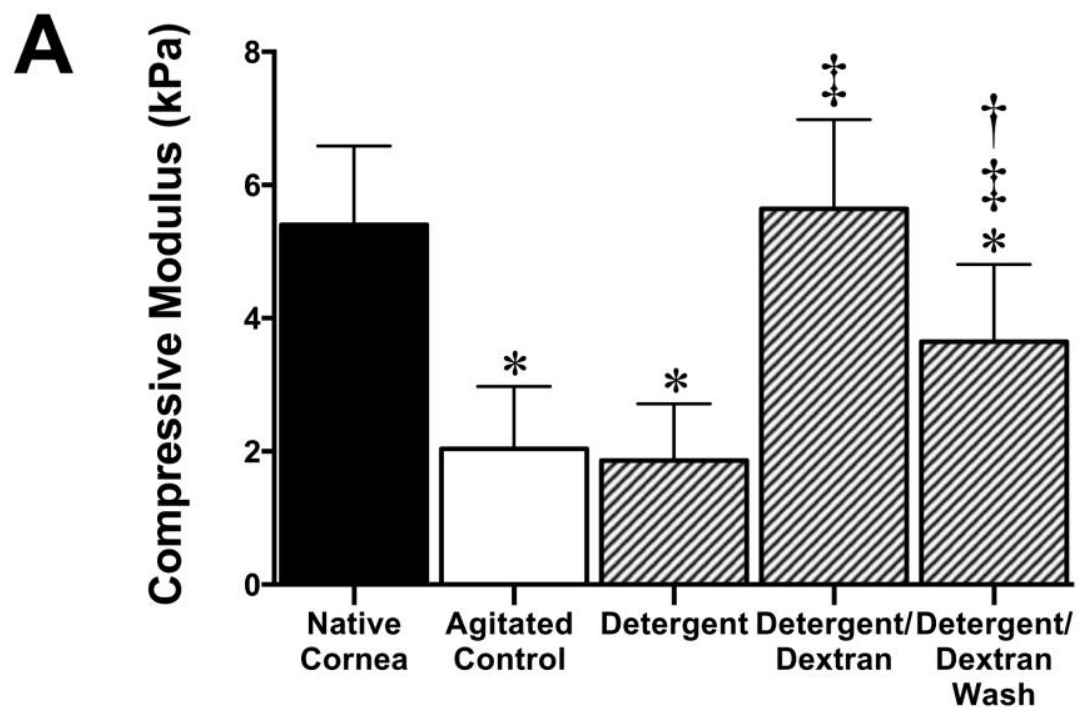

B

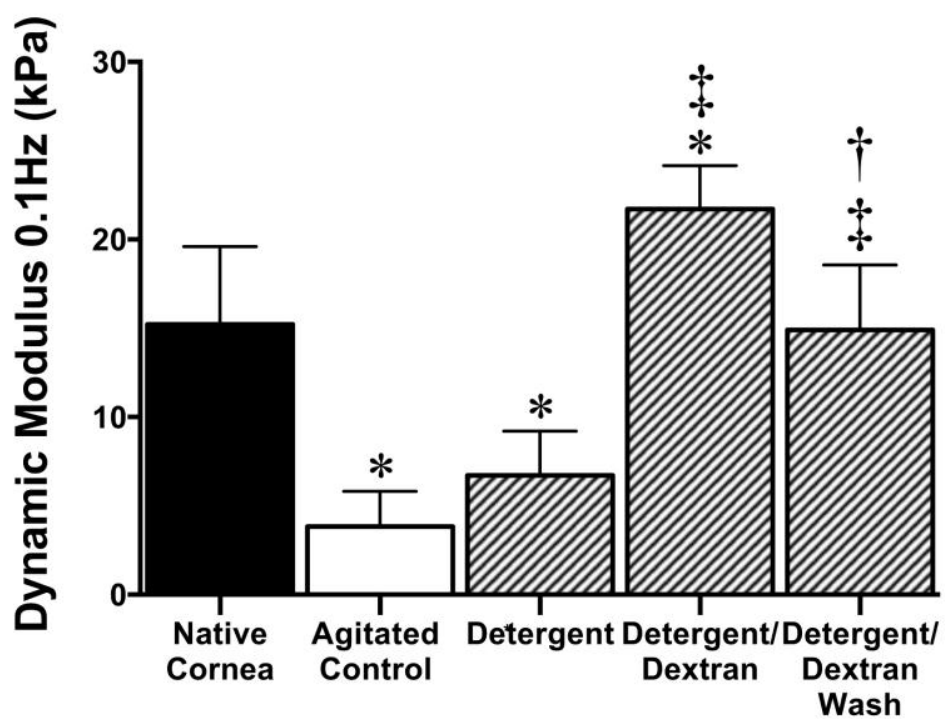

C

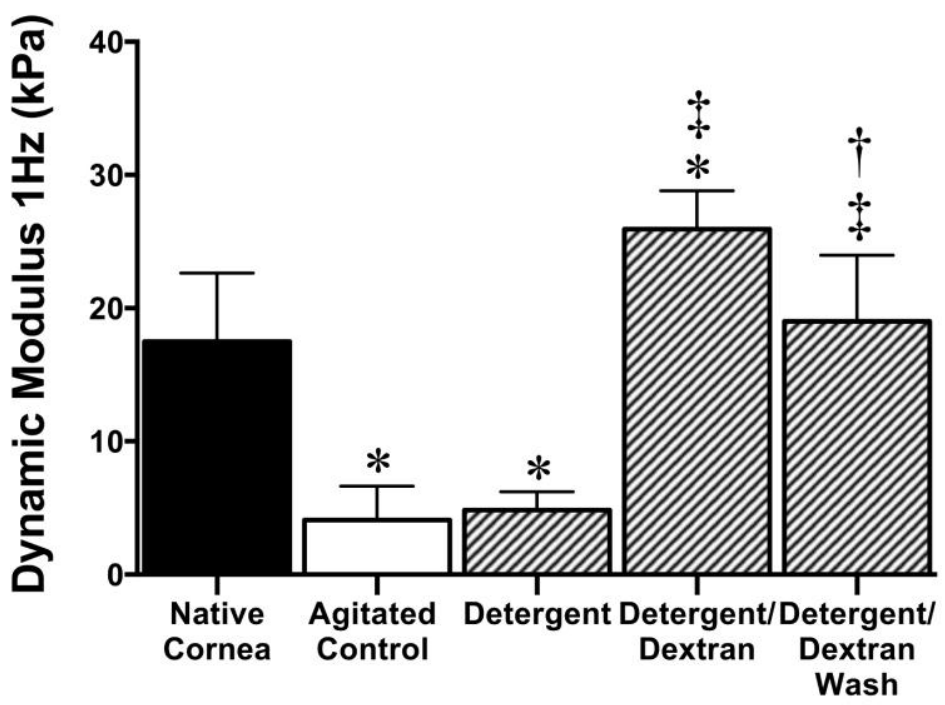

Controls

Treated 
Figure 5: (A) Compressive modulus, (B) dynamic modulus at $0.1 \mathrm{~Hz}$ and (C) $1 \mathrm{~Hz}$ of control and decellularized corneas $(n=10, \pm$ standard deviation, * represents significant difference compared to native cornea, $\downarrow$ represent significant difference compared to detergent, $\uparrow$ represents significant difference compared to detergent/dextran, $p<0.05$ ). 


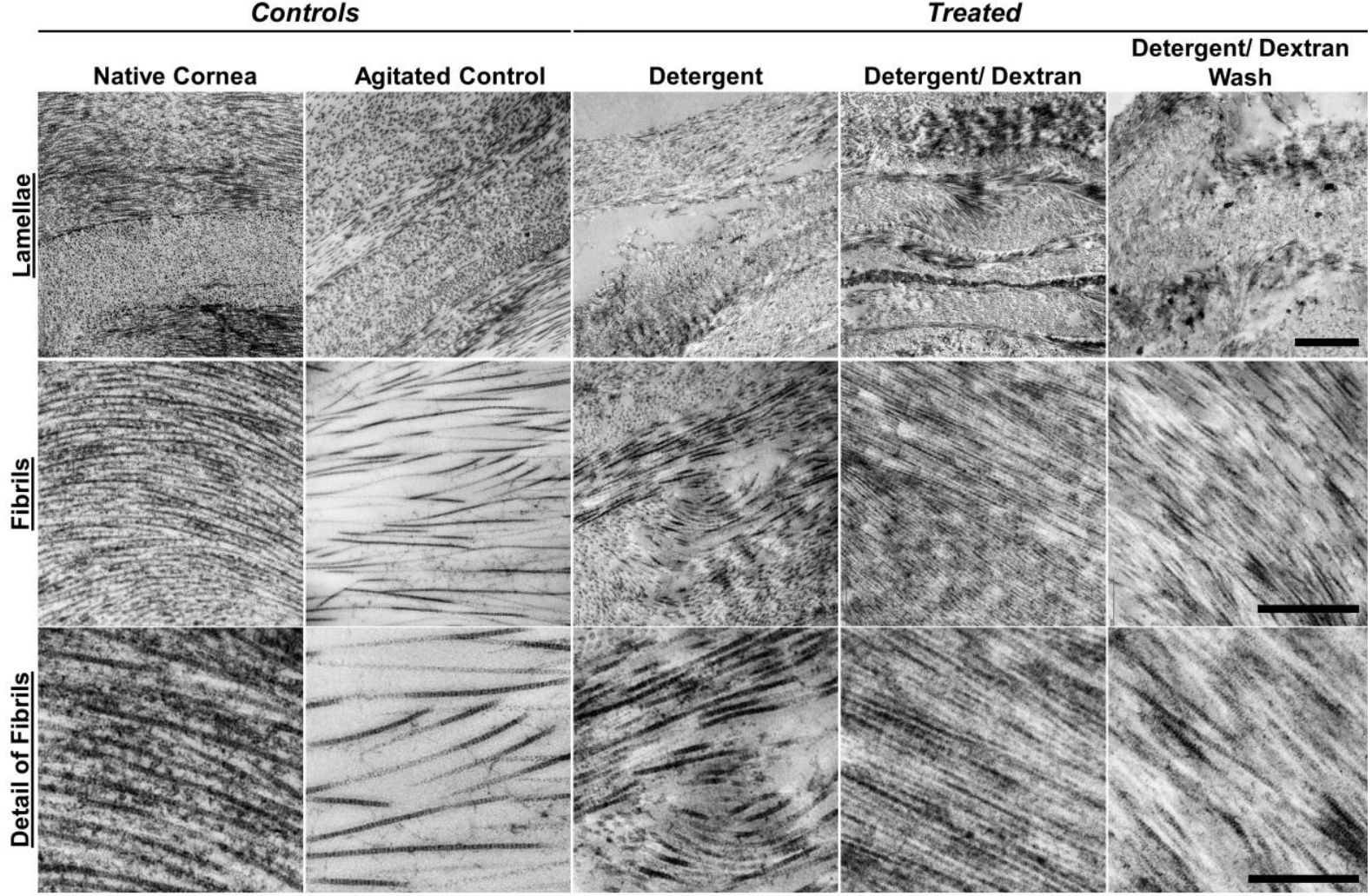

Figure 6: Transmission electron microscopy images of control and decellularized corneas; images depict collagen lamellae banding patterns, scale bar $=2 \mu \mathrm{m}$, collagen fibril bundles, scale bar $=1 \mu \mathrm{m}$, detail of fibrils, scale bar $=0.5 \mu \mathrm{m}$. 
A

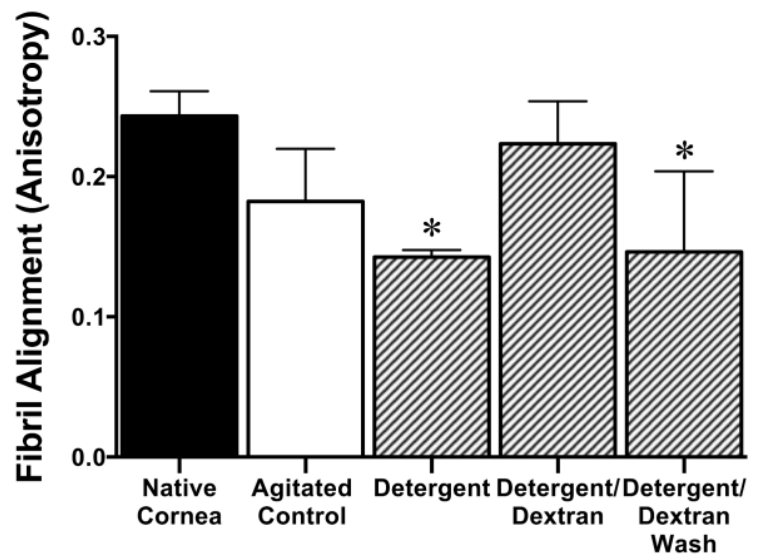

B

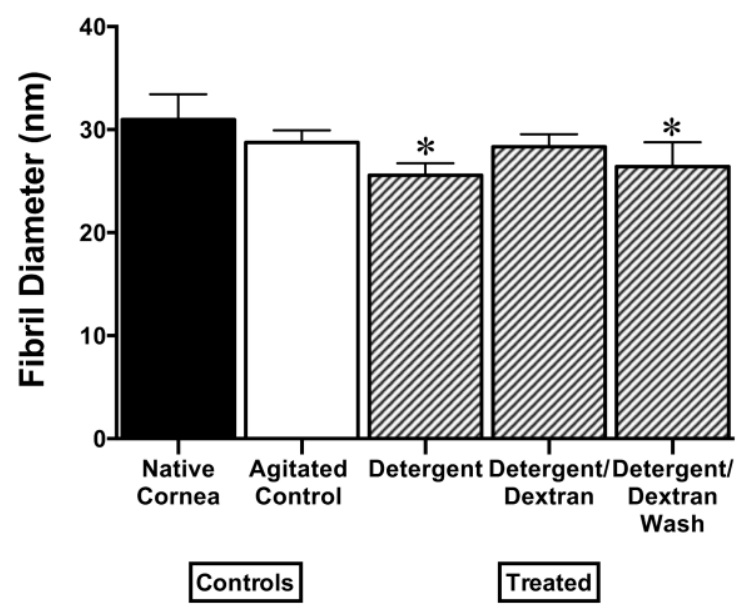

Figure 7: (A) Quantification of collagen fibril alignment and (B) collagen fibril diameter. (n $=3 / 4, \pm$ standard deviation, $*$ represents significant difference compared to native cornea, $p<$ $0.05)$. 


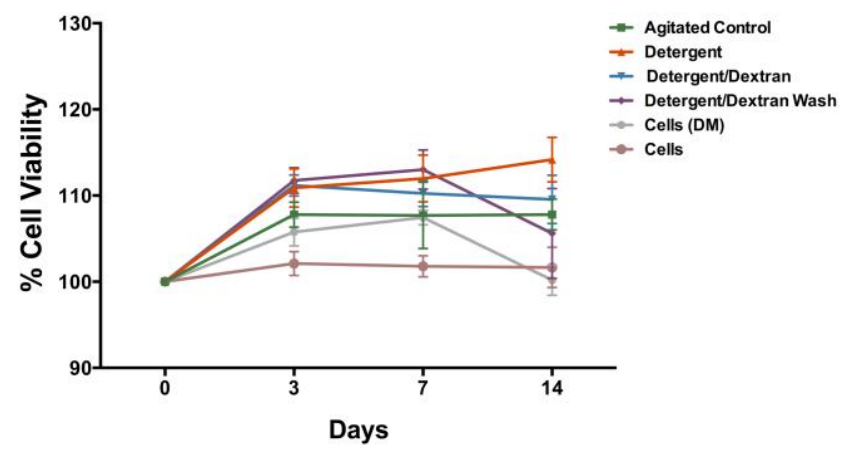

Figure 8: Percentage of viable cells relative to day 0 as measured by cell proliferation at day $0,3,7$ and 14. ( $n=6, \pm$ standard deviation). 